\title{
Survey of Wild Edible Mushrooms in Champhai District, Mizoram, India
}

\author{
Zarzoliana Ralte*, Sobita Simon and Abhilasha A. Lal
}

Department of Plant Pathology, Sam Higginbottom University of Agriculture, Technology and Sciences, Prayagraj 211007, (U.P), India

*Corresponding author

\section{A B S T R A C T}

\begin{tabular}{l} 
Key w o r d s \\
Wild mushrooms, \\
Ethnic, Survey \\
\hline Article Info \\
\hline $\begin{array}{l}\text { Accepted: } \\
15 \text { February } 2020 \\
\text { Available Online: } \\
10 \text { March } 2020\end{array}$ \\
\hline
\end{tabular}

A survey was carried out to study the diversity of Macrofungi from the forest of Champhai, Mizoram, Northeast India. 17 (seventeen) species of edible wild mushrooms were collected. The identified specimens were from the families - Russulaceae, Polyporaceae, Boletaceae, Lyophyllaceae, Agaricaceae, Auriculariaceae, Marasmiaceae, Gomphaceae, Schizophyllaceae, Elaphomycetaceae. The species were identified based on their morphology. The ethnic tribal people have extensive ethnomycological knowledge based on which they collect and sell the edible ones.

\section{Introduction}

The term mushrooms (macrofungi) or macromycetes are fleshy, spore- bearing fruiting bodies of fungi, which typically appear above ground after rain ${ }^{1}$. Mushrooms producing prominent sporocarps are categorized as gilled fungi, bracket fungi, coral fungi, jelly fungi, birds nest fungi and puffballs ${ }^{2}$. They can be classified into three basic ecological groups: mycorrhizal, parasitic and saprophytic ${ }^{3}$. Numerous varieties of edible mushrooms exist in nature with more than 1,100 species recorded so far ${ }^{4}$, however, less than $25 \%$ are widely accepted as food and only a few have attained the level of an item of commerce ${ }^{5}$. In North East India, wild mushrooms are sold in local markets and are known to provide sustenance to the local people and forest dwellers during the lean period (rainy season) ${ }^{6}$.

Mizoram has a mycophilic society comprising of ethnic tribe that have extensive traditional mycological knowledge. The varieties of wild edible mushrooms consumed by the people are harvested or collected from wild habitats and no efforts have been made to cultivate them for commercial sale ${ }^{7}$. However, a report on death happens annually because of mushroom poisoning due to lack of knowledge. In this survey we have collected wild mushrooms from the forest and locally available in the market. The present study was 
therefore documenting the edibles mushroom to provide baseline data for these fungi so that future monitoring can be established and to explore for their bioprospection.

\section{Materials and Methods}

\section{Study area}

Champhai is a border town in Mizoram State, in far North eastern India. It is the headquarters of Champhai district, one of the eight districts in the state. It is located on the Indo-Myanmar border and is situated in a strategically important location. Because of this, it is the main business corridor for India and Myanmar in the area. The area of Champhai is 3,185.83 square kilometres $(1,230 \mathrm{sq} \mathrm{mi})$. The average annual rainfall is $1,814 \mathrm{~mm}$ (71.4 in).

Champhai has a moderate climate. In winter, the temperature varies from $10{ }^{\circ} \mathrm{C}$ to $20^{\circ} \mathrm{C}$ and in summer, and between $15^{\circ} \mathrm{C}$ and $30^{\circ} \mathrm{C}$ in winter. Elevation from sea level at $1,678 \mathrm{~m}$ $(5,505 \mathrm{ft})$.a. The area comprises varied geographical features like agricultural plains, hilly terrains \& forests. The total forest cover of the district is 240832 hectares. Wild mushrooms were collected at four location from the forest of Hmunhmeltha, Mualkawi, Ngur and Zote.

\section{Collection and survey of wild mushrooms}

The survey was carried out for a short period of time in four selected sites viz. Mualkawi, Zote, Hmunhmeltha and Ngur. The fleshy fungi were collected from different habitats. The different forests mentioned above are evergreen, coniferous and deciduous i.e mixed type of forests impregnated with decaying wood and rotting plant parts, termite nest, cow dungs, leaf litters etc. The specimens were found attached to various substrata.
The collection of specimens was also done from different markets in localities in order to gather information in regards to their place of occurrence.

\section{Identification of the wild mushrooms specimens}

The collected specimens were identified according to standard macroscopic characteristics through consultation with appropriate literature and anatomical features into accounts viz [Mata et al., 2010 and Verma et al., 2013) and standard manuals for mushroom identification like www.mushroomexpert.com, www.mycokey. com, mycobank.org and FungusID.

The macroscopic characteristics such as shape, size and colour of basidiocarps were described from fresh specimens. Spore prints were also taken on a white paper to clarify the identification.

\section{Results and Discussion}

\section{Species list}

Species diversity of macrofungi is related to particular habitats and ecosystem. It was found that environmental factors like light, temperature and $\mathrm{RH}$ greatly influenced the growth and development of macrofungi.

During this short period of time ( JuneAugust 2019) 17 edible wild mushrooms were collected. The identified specimens were from the families - Russulaceae (35\%), Polyporaceae (5\%), Boletaceae (5\%), Lyophyllaceae (11\%), Agaricaceae (5\%), Auriculariaceae $(11 \%)$, Marasmiaceae $(5 \%)$, Gomphaceae (5\%), Schizophyllaceae (5\%), Elaphomycetaceae $(5 \%)$. The study revealed that in the small area study sites diversity is extensively vast. 


\section{Species description}

Edible Mushrooms:
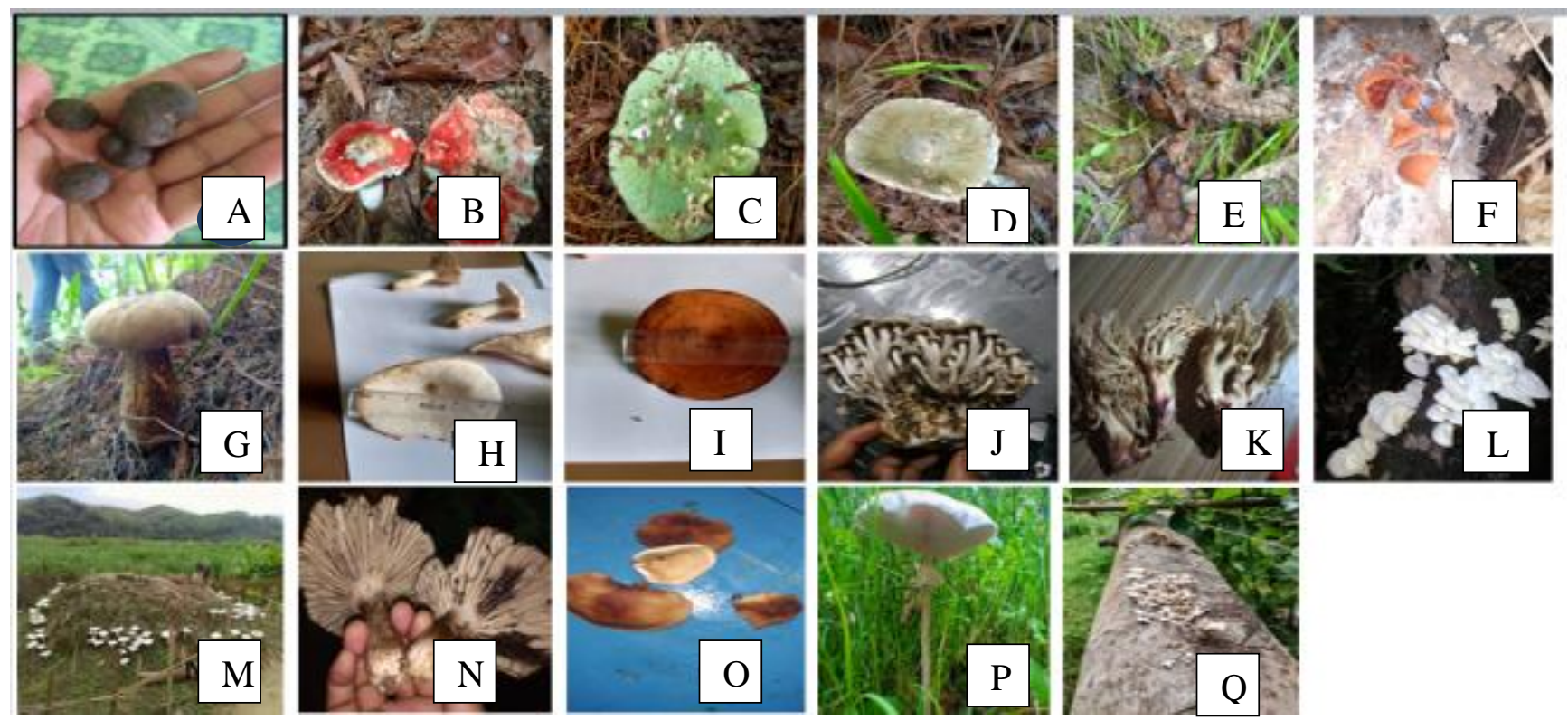

Photoplate 1: a) Elaphomyces anthracinus b) Russula subfragilliformis c) Russula virescens

d) Russula cyanothoxa e) Exidia recisa f) Auricularia auricula-judae g) Boletus quercicola

h) Lactarius piperatus i) Lactifluus corrugis j) Hypsizygus tessellatus k) Ramaria sp. 1) Lentinus tigrinus m) Termitomyces heimii n) Russula nigricans o) Lentinula lateria p) Macrolepiota dolichaula q) Schizophyllum commune.

\section{Elaphomyces anthracinus}

Irregularly globose, $2-5 \mathrm{~cm}$, the thick outer skin is brown to nearly black or purplish black and is smooth. The interior spore mass is grey and moist initially, drying out and trning purple- black as spores mature. Ectomycorrhizal, hypogeal (below the soil surface).

\section{Russula subfragilliformis}

Cap 5-10 cm broad, convex to nearly flat, often with a slightly sunken center, more or less smooth, red to pinkish red, dry but sticky and shiny when wet, incurved margin, unlined. Flesh white, thick, firm, brittle. Gills almost distant, white to pale cream-yellow, bruising and discoloring on exposure. Stem (stipe) 2-6 cm long, 1-2 cm long, thick, equal, dry, brittle, firm, white but soon partly pink, solid, becoming hollow. Spore print white. Terrestial, myrcorrhizal with oak, pines and mainly found in coniferous forest.

\section{Russula virescens}

Cap 5-12 cm; round to convex when young, becoming broadly convex to flat to uplifted with a shallow depression; dry; velvety; the surface soon cracking up into small patches. Gills attached to the stem or nearly free from it at maturity; close or crowded; white to cream. Stem 3-9 cm long; $1.5-3 \mathrm{~cm}$ thick; brittle; dry; smooth; white. Flesh is white; brittle; thick; not changing when sliced. Spore Print is White. Mycorrhizal with hardwoods (but collected it under conifers with no hardwoods nearby); growing alone or gregariously. 


\section{Russula cyanothoxa}

Cap 4-15 cm; convex when young, becoming broadly convex to flat with a shallow depression; dry or slightly moist; smooth, pinkish purple to green or olive green--or with these and other shades mottled; the margin usually not lined. Gills attached or slightly running down the stem; close or nearly distant, white. Stem 5-11 cm long; 1-3 cm thick; white, but occasionally flushed with lilac; brittle; dry; smooth. Flesh is white, brittle and thick. Spore Print is white. Mycorrhizal with hardwoods or conifers; growing alone, scattered, or gregariously.

\section{Exidia recisa}

Individual fruiting bodies are $1-4.5 \mathrm{~cm}$ across, but are typically clustered together to appear as a larger mass; gelatinous but fairly firm; lobed, with concave depressions separated by ridges; usually featuring a small pseudostem - or at least attached more or less centrally at a pinched point; dark brown, often with a purplish cast; bald; under surface dull brown; blackening along the edges and ridges when dried out. Saprobic, growing on recently fallen hardwood sticks and branches (especially on the wood of oaks).

\section{Auricularia auricula - judae}

Wavy and irregular; often more or less earshaped but sometimes oval, elliptical, cupshaped, or irregular in outline; $2-5 \mathrm{~cm}$ across; thin; usually gathered together and attached at a central or lateral position; upper, fertile surface brown to reddish brown, bald, sometimes wrinkled in places; lower, sterile surface finely hairy when fresh and young, creating a whitish bloom over the brown to reddish brown surface; flesh thin, gelatinousrubbery; entire fruiting body becoming hard and black when dried out. Spore Print is white. Saprobic on decaying hardwood sticks, logs, and stumps.

\section{Boletus quercicola}

Cap is 4-9 cm; convex in the button stage, becoming broadly convex to nearly flat; velvety, bald, light to dark orangish brown; often somewhat paler toward the margin. Pore Surface is whitish and "stuffed" at first; becoming pale yellow and eventually olive yellow; not bruising; at maturity with $2-3$ round pores per $\mathrm{mm}$; tubes to $2 \mathrm{~cm}$ deep. Stem is $4-8 \mathrm{~cm}$ long; $2-3 \mathrm{~cm}$ thick; usually swollen and club-shaped, finely reticulate brownish in colour. Flesh is white to brown, firm and unchanging when sliced. Mycorrhizal with conifers, especially spruces and reportedly occasionally with hardwoods; growing alone, scattered, or gregariously.

\section{Lactarius piperatus}

Cap $3-14 \mathrm{~cm}$, broadly convex, becoming flat, shallowly depressed, dry, the margin even, bald, white or whitish, sometimes discoloring a little yellowish or brownish with age. Flesh white, thick, hard, sometimes discoloring yellowish with age. Milk (latex) copious, white, unchanging after exposure, or changing slowly to yellowish. Gills attached to the stem or running slightly down it, very crowded, forking frequently, white becoming pale cream. Stalk 2-7 cm long, 1-2.5 cm thick, white, more or less equal, or tapering a little to base. Spore print white to off white. Mycorrhizal with oaks and other hardwoods; growing scattered, gregariously, or sometimes in dense troops.

\section{Lactifluus volemus}

Cap 4-20 cm broad, convex at first becoming plane or shallowly depressed, minutely velvety to nearly smooth, dry, usually dark brownish red to dark brick. Flesh whitish to yellowish; staining slowly brown when sliced, thick, firm but brittle. Latex white, copious, slowly staining brown. Gills adnate to slightly decurrent, close, orange to yellowish or 
brownish, discoloring brown where injured. Stalk 3-11 cm long, $1.5-3 \mathrm{~cm}$ thick, colored more or less like the cap, brown to reddish brown or paler equal, solid. Spore print is white. Mycorrhizal with oaks and other hardwoods, as well as conifers; growing alone, scattered, or gregariously.

\section{Hypsizygus tessellatus}

Cap is $2-5 \mathrm{~cm}$; convex, becoming broadly convex with a slightly inrolled margin; dry; whitish to buff or very pale tan; sometimes "tessulated" with watery spots when fresh and young. Gills is attached to the stem; close; short-gills frequent; whitish; not bruising. Stem is $3-8 \mathrm{~cm}$ long, $1-2 \mathrm{~cm}$ thick; equal or slightly club-shaped; very finely silky; whitish to very pale tan. Flesh is firm, white and unchanging when sliced. Spore print is white. Saprobic, usually growing in clusters of two or three.

\section{Ramaria sp.}

Fruiting Body is $2-12 \mathrm{~cm}$ high; up to $10 \mathrm{~cm}$ wide; repeatedly branched. Branches is 1-5 mm thick; smooth; white, often developing dirty pinkish hues with age; tips bluntly pointed, colored like the sides. Base when present is $5-3 \mathrm{~cm}$ long; to about $1 \mathrm{~cm}$ wide; whitish, sometimes becoming pinkish or yellowish; finely fuzzy. Flesh is whitish, brittle and fragile. Spore Print in White. Probably saprobic, growing terrestrially or rarely from well decayed wood; scattered or gregarious.

\section{Lentinus tigrinus}

Cap is $1-3 \mathrm{~cm}$ wide; broadly convex, with a prominent, navel-like central depression; dry; fibrillose-scaly with small, dark brown scales over a tan to brown ground; the margin incurved and not lined. Gill running down the stem; crowded; edges becoming slightly serrated; short-gills frequent; white to creamy. Stem is $2-4 \mathrm{~cm}$ long; $2-5 \mathrm{~mm}$ wide; equal or slightly tapered toward the base; dry; scaly with fine brown scales like those on the cap when fresh and young, but often losing the scales quickly and appearing fibrillose. Whitish toward the apex; brownish to brown below, ephemeral ring zone when fresh and young. Flesh is whitish and unchanging when sliced. Spore Print is White. Saprobic, growing alone, scattered, or, more frequently, gregariously to loosely clustered on the wood of hardwoods.

\section{Termitomyces heimii}

Cap 4-8 $\mathrm{cm}$ in diameter, white with the umbo region when young, grey and brownish grey when mature, context fleshy white, glabrous, surface smooth, convex to plano-convex with eroded margin, prominently sub-umbonate when young. Stalk white, smooth, cylindrical, equal and fleshy measuring $7-18 \mathrm{~cm}$ in length and $1-2 \mathrm{~cm}$ in width. Lamellae present, white to pink, crowded and free. Spore print pink, with a brownish tinge. Annulus present. Volva absent. Mycorrhizal, growing in subterranean termites soil.

\section{Russula nigricans}

Cap is 5-20 cm; broadly convex when young, later flat with a central depression, dry; more or less smooth, but with a waxy feel; initially whitish but soon discoloring to brownish and eventually black; the skin not peeling easily. Gills is attached or running very slightly down the stem; thick; distant or nearly so; white to cream; bruising and discoloring slowly to grayish and then blackish. Stem is 3-8 cm long; 1-4 cm thick; whitish at first, but soon darkening like the cap; bruising reddish, then blackish over the course of as much as half an hour; fairly smooth. Mycorrhizal with hardwoods or conifers; growing alone, scattered, or gregariously. 


\section{Lentinula lateria}

Fruiting body tan to reddish brown, margin slightly in rolled or wavy. Flesh white to cream. Gills free and white. Stalk tan to reddish brown covered with scales when mature. Spore print white to cream. Saprobic, growing alone, scatter on tree branch, stump mostly chesnut tree.

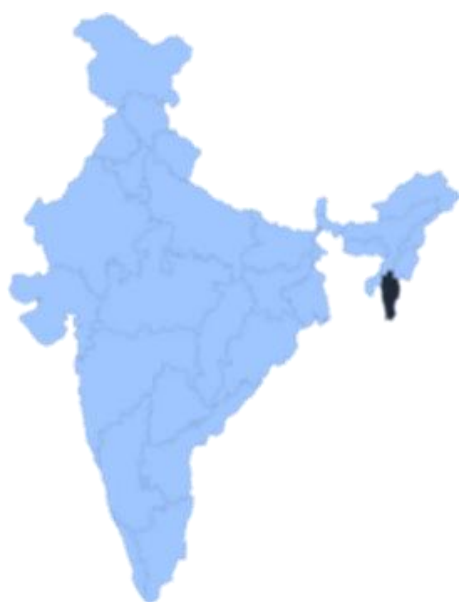

Plate.1 India map highlighting Mizoram State

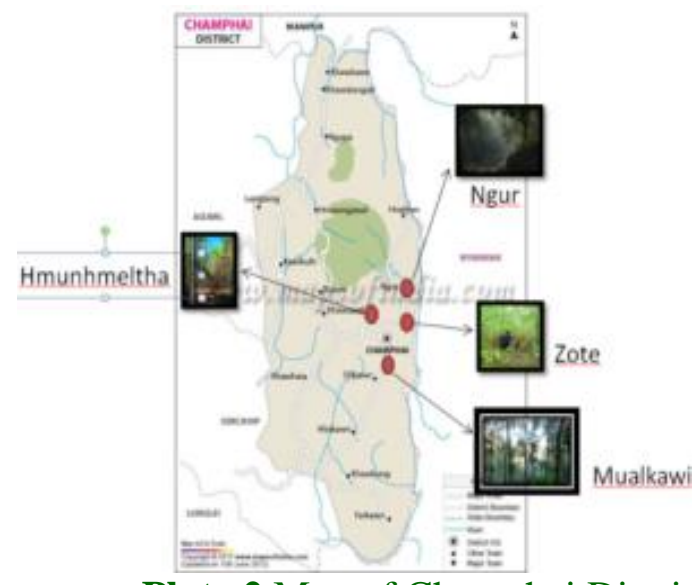

Plate.2 Map of Champhai District showing the study area

Fig.1

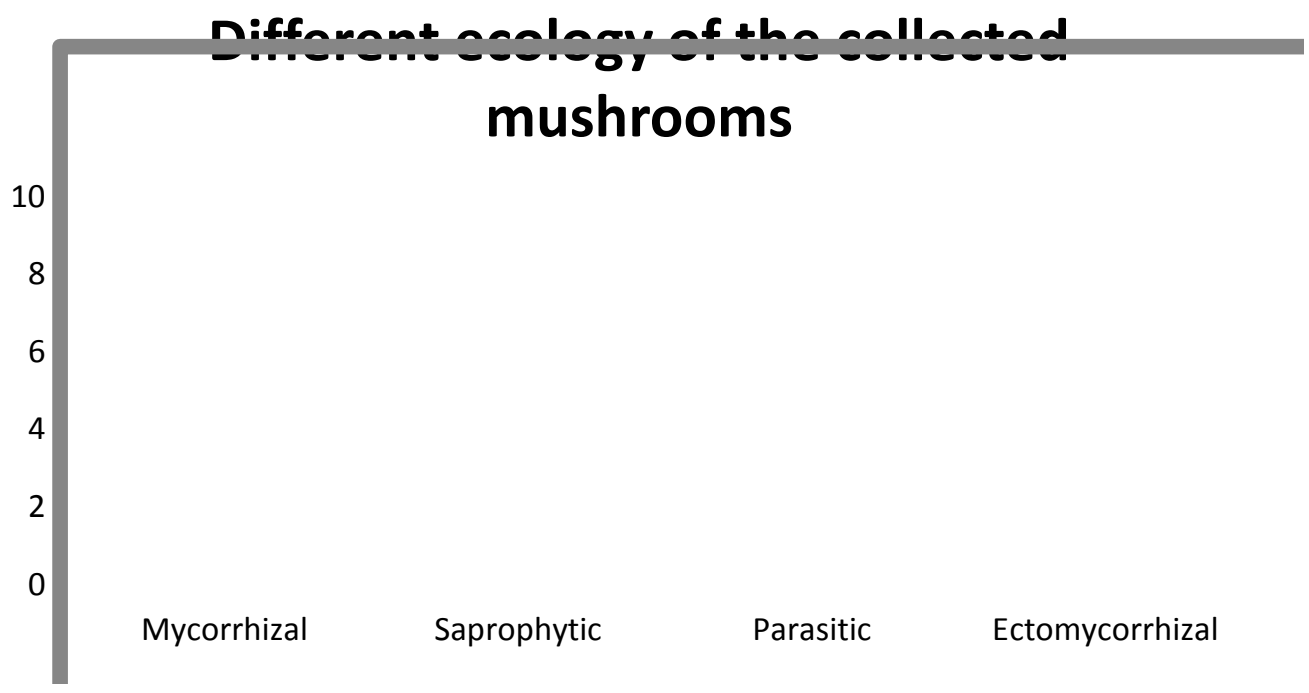


Table.1 List of mushroom with family, habitat and place of collection

\begin{tabular}{lllll}
\hline Sl.No & Scientific Name & Family & Habitat & Place of collection \\
\hline 1. & Elaphomyces anthracinus & Elaphomycetatceae & Hypogeal & Local Market \\
2. & Russula subfragillifromis & Russulaceae & Soil & Hmunhmeltha \\
3. & Russula virescens & Russulaceae & Soil & Hmunhmeltha \\
4. & Russula cyanothoxa & Russulaceae & Soil & Hmunhmeltha \\
5. & Exidia recisa & Auriculariaceae & Wood & Zote \\
6. & Auriclularia auricula-judae & Auriculariaceae & Wood & Ngur \\
7. & Boletus quercicola & Boletaceae & Soil & Zote \\
8. & Lactarius piperatus & Russulaceae & Soil & Zote \\
9. & Lactifluus corrugis & Russulaceae & Soil & Zote \\
10. & Hypsizygus tesselatus & Lyophyllaceae & Wood & Ngur \\
11. & Ramaria sp. & Gomphaceae & Soil & Ngur \\
12. & Lentinus tigrinus & Polyporaceae & Wood & Ngur \\
13. & Termitomyces heimii & Lypophyllaceae & Termite Soil & Mualkawi \\
14. & Russula nigricans & Russulaceae & Soil & Mualkawi \\
15. & Lentinula lateria & Marasmiaceae & Wood & Local market \\
16. & Macrolepiota dolichaula & Agaricaceae & Soil & Zote \\
17. & Schizophyllum commune & Schizophyllaceae & Wood & Zote, Ngur \\
\hline
\end{tabular}

\section{Macrolepiota dolichaula}

Cap 5-18 cm broad, at first oval, then expanding to convex or plane with umbonate at the center, surface dry, cap surface smooth at first but soon breaking up into light brown to brown or pinkish brown scales and patches on a white background, more concentrated darker scales at the central umbo margin bearing remnants of veil. Flesh white, thick, soft in age. Gills free, white when young but sometimes discoloring to pinkish white or dingy brownish in old age, broad, close. Stalk white and very tall, $5-20 \mathrm{~cm}$ long, $0.5-2 \mathrm{~cm}$ thick, bulbous at the base. Annulus persistent and membranous, ring collar like and movable, thick. Spore print white. Parasol mushrooms tend to grow alone or scattered in late summer, in woods or at their edges, or in pastures — often on trails.

\section{Schizophyllum commune}

Fruiting Body 1-5 cm wide, fan-shaped when attached to the side of the log, irregular to shell-shaped when attached above or below, upper surface covered with small hairs, dry, white to grayish or tan, under surface composed of gill-like folds that are split down the middle, whitish to grayish, without a stem. Flesh tough, leathery. Spore print white. Saprobic on dead wood or occasionally parasitic on living wood; growing alone or, more frequently, gregariously to clustered; on decaying hardwood sticks and logs (even on planks and boards); year-round (it survives by shriveling up and waiting for more moisture).

In conclusion, a total of 17 edible species of wild mushrooms were identified according to standard protocol.

\section{References}

Ainsworth, G.C., Bisby, Richard, G. \& Kirk, P.M (1950) A Dictionary of the fungi ( $9^{\text {th }}$ editions),CABI Bioscience, U.K.

Ao, T., Deb, C.R., and Khruomo, N (2016) Wild edible Mushrooms of Nagaland, 
India: A Potential Food Resource.

Bates, S.C (2006). A preliminary checklist of Arizona Macrofungi. Canotia 2:47-48.

Boa, E (2004) Non wood Forest Products. FAO, Rome 1- 147.

Harsh N.S.K. and Joshi K (2008) Mushrooms: The vegetables of future. India, Science and Technology.

Hmar Lalrinawmi, Josiah M.C. Vabeikhokhei, Zothanzama, J. and Zohmangaiha (2017). Edible Mushroom of Mizoram, Science Vision 17(3):172-181.

Kumar, R., Pandey, S., Tapwal, A., Rishi, R.R., Giri, K., Mishra, G. (2014) Ethnomycological knowledge on wild mushrooms by tribes of Mokokchung, Nagaland, North East India. The Journal of Ethnobiology and Traditional Medicine 122: 890-899.

Mata M., Penjor D., and Pradhan S. Fungi of Bhutan (2010)NBC.

Mortimer, P.E., Samantha C. Karunarathna, Qiaohong Li, Heng Gui, Xueqing Yang, Xuefei Yang, Jun He, Lei Ye, Jiayu Guo, Huili Li, Phongeun Sysouphanthong, Dequn Zhou, Jianchu $\mathrm{Xu}$ and Kevin D. Hyde (2012). Prized edible Asian mushrooms: ecology, conservation and sustainability. Fungal Diversity
56(1):31-47.

Paul Stamets (2000) Growing Gourmet and Medicinal Mushrooms ( $3^{\text {rd }}$ edition).

Polashree Khaund and S R Joshi (2013) Wild edible macrofungal species consumed by the Khasi tribe of Meghalaya, India. Indian Journal of Natural Products and Resources, 4(2):197204.

Salam S. and Jamir N.S. (2018) Wild Edible Fungi Sold in Local Markets of Ukhrul District of Manipur, India.

Sarma, T.C., Sarma, I and Patiri, B.N (2010) Wild edible mushrooms used by some ethnic tribes of Western Assam. An International Quarterly Journal of Life Sciences 3: 613-625.

Smith, J (1972) Commercial mushroom production. Process Biochemistry 7:24-26.

Tapwal, A., Kumar, R., and Pandey S (2013) Diversity and frequency of macrofungi associated with wet ever greentropical forest in Assam, India. Biodiversitas 14(2):73-78.

Verma, B.N., Prasad, P.K., Sahu, K.K Mushrooms: Edible and Medicinal. Cultivation, Conservation, Strain improvement with their Marketing (2008).

\section{How to cite this article:}

Zarzoliana Ralte, Sobita Simon and Abhilasha A. Lal. 2020. Survey of Wild Edible Mushrooms in Champhai District, Mizoram, India. Int.J.Curr.Microbiol.App.Sci. 9(03): 21592166. doi: https://doi.org/10.20546/ijcmas.2020.903.247 